\title{
Percutaneous Endoscopic Gastrostomy Tube Insertion in Neurodegenerative Disease: A Retrospective Study and Literature Review
}

\author{
Pamela Sarkar ${ }^{1,2}$, Alice Cole ${ }^{2}$, Neil J. Scolding ${ }^{1,2}$ and Claire M. Rice ${ }^{1,2}$ \\ ${ }^{1}$ Department of Neurology, Southmead Hospital, Bristol, ${ }^{2}$ Clinical Neuroscience, School of Clinical Sciences, University of Bristol, Bristol, UK
}

Background/Aims: With the notable exceptions of dementia, stroke, and motor neuron disease, relatively little is known about the safety and utility of percutaneous endoscopic gastrostomy (PEG) tube insertion in patients with neurodegenerative disease. We aimed to determine the safety and utility of PEG feeding in the context of neurodegenerative disease and to complete a literature review in order to identify whether particular factors need to be considered to improve safety and outcome.

Methods: A retrospective case note review of patients referred for PEG insertion by neurologists in a single neuroscience center was conducted according to a pre-determined set of standards. For the literature review, we identified references from searches of PubMed, mainly with the search items "percutaneous endoscopic gastrostomy" and "neurology" or "neurodegenerative disease."

Results: Short-term mortality and morbidity associated with PEG in patients with neurological disease were significant. Age greater than 75 years was associated with poor outcome, and a trend toward adverse outcome was observed in patients with low serum albumin.

Conclusions: This study highlights the relatively high risk of PEG in patients with neurodegenerative disease. We present points for consideration to improve outcome in this particularly vulnerable group of patients. Clin Endosc 2017;50:270-278

Key Words: Percutaneous endoscopic gastrostomy; Neurodegenerative diseases; Multiple sclerosis; Parkinson disease; Motor neuron disease

\section{INTRODUCTION}

Percutaneous endoscopic gastrostomy (PEG) has been a recognized method of administration of long-term enteral feeding since the 1980s. ${ }^{1}$ The continuity of feeding and aspiration rates of PEG compare favorably with those of nasogastric feeding. ${ }^{2}$ PEG feeding may be considered if nutritional intake is expected to be qualitatively or quantitatively inadequate for a period exceeding 2 to 3 weeks, ${ }^{3}$ and increases in serum albu-

Received: July 22, 2016 Revised: August 16, 2016

Accepted: September 9, 2016

Correspondence: Claire M. Rice

Clinical Neuroscience, School of Clinical Sciences, University of Bristol, Level 1 Learning and Research Building, Southmead Hospital, Bristol, UK

Tel: +44-117-414-6695, Fax: +44-117-414-9475, E-mail: c.m.rice@bristol.ac.uk

(cc) This is an Open Access article distributed under the terms of the Creative Commons Attribution Non-Commercial License (http://creativecommons.org/ licenses/by-nc/3.0) which permits unrestricted non-commercial use, distribution, and reproduction in any medium, provided the original work is properly cited. min, a marker of nutritional status, have been demonstrated after PEG tube placement. ${ }^{4}$

The potential for PEG as a means of artificial enteral nutrition in patients with neurological disease was quickly appreciated. ${ }^{5}$ In these circumstances, dysphagia-with consequent risk of airway obstruction, dehydration, weight loss, salivary dribbling, and aspiration pneumonia ${ }^{4}$-is the most common indication for artificial enteral nutrition. ${ }^{6}$ The effort of eating and time taken to feed during the day may be considerable, with each mouthful taking 12 to 15 times longer to chew. However, prior to insertion of an enteral feeding tube, the clinical context, diagnosis, prognosis, ethical issues, anticipated effect on quality of life, and the patient's wishes must be taken into account. ${ }^{2}$

Postprocedure morbidity and mortality of PEG tube insertion were reported previously, but few studies examined patients with neurological disease in isolation (Table 1). 2,45,7-28 $^{-1}$ The overall complication rate after endoscopic placement 
Table 1. Historical Comparison with Selected Series Investigating Safety and Utility of Percutaneous Endoscopic Gastrostomy Tube Insertion

\begin{tabular}{|c|c|c|c|c|c|c|}
\hline Study & Indication, \% & $\begin{array}{l}\text { Date of } \\
\text { series }\end{array}$ & $\begin{array}{l}\text { Size of } \\
\text { series, } n\end{array}$ & $\begin{array}{l}\text { Mean age, } \\
\text { yr }\end{array}$ & $\begin{array}{l}\text { Complication } \\
\text { rate, } \%\end{array}$ & $\begin{array}{c}\text { 30-day } \\
\text { mortality, \% }\end{array}$ \\
\hline $\begin{array}{l}\text { Löser et al. } \\
(1998)^{2}\end{array}$ & Neurological (42), ENT (28), medical (30) & 1991-1995 & 210 & 61.3 & 24 & 0 \\
\hline $\begin{array}{l}\text { Hull et al. } \\
(1993)^{5}\end{array}$ & $\begin{array}{l}\text { Cerebrovascular disease (33), MND (27), MS (8), } \\
\text { head and neck cancer (16), miscellaneous (16) }\end{array}$ & 1988-1992 & 49 & 64 & 22 & 2 \\
\hline $\begin{array}{l}\text { Rabeneck et al. } \\
(1996)^{21}\end{array}$ & $\begin{array}{l}\text { Cerebrovascular disease (19), other organic } \\
\text { neurological disease (29), head and neck cancer } \\
\text { (16), miscellaneous (36) }\end{array}$ & 1990-1992 & 7,369 & 68.1 & 4 & 23.5 \\
\hline $\begin{array}{l}\text { Sanders et al. } \\
(2000)^{13}\end{array}$ & $\begin{array}{l}\text { Oropharyngeal malignancy (18), stroke (33), } \\
\text { dementia (29), miscellaneous (20) }\end{array}$ & $1992-1997$ & 361 & 66.9 & 29 & 28 \\
\hline $\begin{array}{l}\text { Leeds et al. } \\
(2010)^{22}\end{array}$ & $\begin{array}{l}\text { Cognitive impairment (2), stroke (11), oropha- } \\
\text { ryngeal cancer (30), neurological cancer (34), } \\
\text { other ( } 23 \text { ) }\end{array}$ & $2004-2007$ & 233 & 61.6 & NA & 10.7 \\
\hline $\begin{array}{l}\text { Tominaga et al. } \\
(2010)^{18}\end{array}$ & $\begin{array}{l}\text { Malignant disease (27), cerebrovascular disease } \\
(32), \text { neurodegenerative disease (23), poor } \\
\text { recovery post operation (16), dementia (14) }\end{array}$ & $1998-2007$ & 84 & 60.3 & 46 & 0 \\
\hline $\begin{array}{l}\text { Arora et al. } \\
(2013)^{16}\end{array}$ & $\begin{array}{l}\text { Malnutrition (18), stroke (20), other neurological } \\
\text { indication (20), head and neck cancer (5), de- } \\
\text { mentia (5), head trauma (5), miscellaneous (27) }\end{array}$ & 2006 & 181,196 & 71 & NA & 10.8 \\
\hline $\begin{array}{l}\text { Burney et al. } \\
(2015)^{11}\end{array}$ & Head and neck cancer (100) & $1997-2010$ & 560 & 59.6 & 18 & 0 \\
\hline $\begin{array}{l}\text { Khokhar et al. } \\
(2005)^{12}\end{array}$ & $\begin{array}{l}\text { Cerebrovascular disease (96), Parkinson's disease } \\
\text { (3), malignancy (1) }\end{array}$ & $1995-2004$ & 182 & $\mathrm{NA}^{\mathrm{a})}$ & 15 & 0 \\
\hline $\begin{array}{l}\text { Luman et al. } \\
(2001)^{9}\end{array}$ & $\begin{array}{l}\text { Cerebrovascular disease (60), Parkinson's and } \\
\text { neuromuscular disease (11), nasopharyngeal } \\
\text { and gastrointestinal malignancy (25), head } \\
\text { injury (4) }\end{array}$ & $1995-2000$ & 181 & $\begin{array}{l}\text { Median } \\
70.5\end{array}$ & 56 & 11.5 \\
\hline $\begin{array}{l}\text { Janes et al. } \\
(2005)^{17}\end{array}$ & $\begin{array}{l}\text { Cerebrovascular disease, nasopharyngeal ma- } \\
\text { lignancy, MS, MND (information regarding } \\
\text { proportions NA) }\end{array}$ & 2001-2002 & 112 & 67.5 & 33 & 22 \\
\hline $\begin{array}{l}\text { Nicholson et al. } \\
(2000)^{23}\end{array}$ & $\begin{array}{l}\text { Cerebrovascular disease (58), other neurological } \\
\text { disease (15\%), oesophageal obstruction (9), } \\
\text { debilitation (18) }\end{array}$ & 1996-1998 & 168 & $\begin{array}{l}\text { Median } \\
70\end{array}$ & 2 & 10 \\
\hline $\begin{array}{l}\text { Zalar et al. } \\
(2004)^{24}\end{array}$ & $\begin{array}{l}\text { Cerebrovascular disease (38), dementia (27), } \\
\text { dysphagia in the elderly (10), MND \& MS (10), } \\
\text { neurosurgical disease (6), Parkinson's disease } \\
\text { (3), CNS neoplasia (3), encephalopathy (2) }\end{array}$ & NA & 99 & 75 & 32 & 1 \\
\hline $\begin{array}{l}\text { Britton et al. } \\
(1997)^{7}\end{array}$ & $\begin{array}{l}\text { MND (38), MS (38), Parkinson's disorders and } \\
\text { related disorders (6), Myotonic dystrophy (6), } \\
\text { Miscellaneous (12) }\end{array}$ & 1992-1995 & 32 & 49 & 41 & 0 \\
\hline $\begin{array}{l}\text { Shimizu et al. } \\
(2007)^{25}\end{array}$ & $\begin{array}{l}\text { MND (29), Parkinson's disease (25), MSA (17), } \\
\text { miscellaneous (32) }\end{array}$ & $2003-2006$ & 157 & NA & 9 & $\mathrm{NA}^{\mathrm{b})}$ \\
\hline $\begin{array}{l}\text { James et al. } \\
(1998)^{10}\end{array}$ & Stroke (100) & 1991-1995 & 126 & $\begin{array}{l}\text { Median } \\
80\end{array}$ & 50 & 28 \\
\hline $\begin{array}{l}\text { Rio et al. } \\
(2010)^{26}\end{array}$ & MND (100) & 1999-2006 & 21 & 61.9 & 33 & 5 \\
\hline $\begin{array}{l}\text { Czell et al. } \\
(2013)^{19}\end{array}$ & MND (100) & NA & 26 & 65 & 15 & 4 \\
\hline $\begin{array}{l}\text { Spataro et al. } \\
(2011)^{8}\end{array}$ & MND (100) & $2000-2007$ & 76 & 59.5 & 0 & 6 \\
\hline
\end{tabular}


Table 1. Continued

\begin{tabular}{|c|c|c|c|c|c|c|}
\hline Study & Indication, \% & $\begin{array}{c}\text { Date of } \\
\text { series }\end{array}$ & $\begin{array}{c}\text { Size of } \\
\text { series, } n\end{array}$ & $\begin{array}{c}\text { Mean age, } \\
\text { yr }\end{array}$ & $\begin{array}{c}\text { Complication } \\
\text { rate, } \%\end{array}$ & $\begin{array}{c}\text { 30-day } \\
\text { mortality, \% }\end{array}$ \\
\hline $\begin{array}{l}\text { Chiò et al. } \\
(1999)^{14}\end{array}$ & MND (100) & $1993-1998$ & 50 & 61.7 & 2 & 2 \\
\hline $\begin{array}{l}\text { Allen et al. } \\
(2013)^{20}\end{array}$ & MND (100) & 2009-2012 & 100 & 61.7 & 16 & 7 \\
\hline $\begin{array}{l}\text { Forbes et al. } \\
(2004)^{27}\end{array}$ & MND (100) & 1989-1998 & 142 & 66.8 & NA & 25 \\
\hline $\begin{array}{l}\text { Mazzini et al. } \\
(1995)^{4}\end{array}$ & MND (100) & 1991-1993 & 31 & 60.9 & NA & NA \\
\hline $\begin{array}{l}\text { Russ et al. } \\
(2015)^{28}\end{array}$ & MND (100) & 2010-2013 & 21 & 58.9 & 29 & 5 \\
\hline $\begin{array}{l}\text { ProGas Study } \\
\text { Group }(2015)^{15}\end{array}$ & MND (100) & 2010-2014 & 169 & 64.2 & 24 & 3 \\
\hline Current study & $\begin{array}{l}\text { Parkinson's disease and related disorders (32), } \\
\text { MS (32), MND (34) }\end{array}$ & 2009-2013 & 40 & 61 & 87.5 & 8 \\
\hline
\end{tabular}

ENT, ear, nose and throat; MND, motor neuron disease; MS, multiple sclerosis; NA, not available; CNS, central nervous system; MSA, multiple system atrophy.

${ }^{\text {a) }}$ Range 55 to 86 years; ${ }^{\text {b) }} 6$-month mortality $6 \%$

Table 2. Published Standards for PEG Insertion

\begin{tabular}{lc}
\hline Standard & Guideline \\
\hline FVC should be recorded for patients with MND patients & ESPEN $^{3}$ \\
$\begin{array}{l}\text { Measurement of renal function, glucose, liver function, bone profile, albumin, clotting, and C-reactive protein } \\
\text { prior to PEG tube insertion }\end{array}$ & NICE $^{30}$ \\
Formal assessments of swallow should be undertaken prior to PEG & NICE $^{30}$ \\
Daily review of stoma site following PEG tube insertion & NICE $^{30}$ \\
\hline
\end{tabular}

PEG, percutaneous endoscopic gastrostomy; FVC, forced vital capacity; MND, motor neuron disease; ESPEN, European Society of Clinical Nutrition and Metabolism; NICE, National Institute for Health and Clinical Excellence.

of an enteral feeding tube is variously reported to be $0 \%$ to $57 \% .{ }^{89}$ Local wound infection is the most common early complication (15\%), ${ }^{3}$ but peristomal abdominal pain, fever, and transient leakage of the stomach contents from the granulating puncture canal may also occur. ${ }^{3}$ Long-term complications may include occlusion of and leakage from the tube and site infections. ${ }^{6,10}$

Mortality rates (30-day postprocedure) of between $0 \%$ and $28 \%$ have been reported. ${ }^{10-13}$ Although not all studies have examined PEG placement in the context of neurological disease, some neurological conditions have been associated with adverse outcome; patients for whom the indication for PEG tube insertion was dysphagia secondary to stroke and dementia had 30 -day mortality rates of $28 \% .^{10,13}$ Other predictors of poor outcome include a history of $>10 \%$ weight loss and forced vital capacity (FVC) $<65 \%$ of the predicted value. ${ }^{14}$ The UK National Confidential Enquiry into Patient Outcome and Death in 2004 estimated that $43 \%$ of PEG-related deaths oc- curred in the first 7 days postprocedure, and aspiration pneumonia was frequently implicated as the cause of death. ${ }^{29}$ Since then, standards and recommendations for PEG insertion have been issued by the European Society of Clinical Nutrition and Metabolism (ESPEN, 2005) ${ }^{3}$ and the National Institute for Health and Clinical Excellence (NICE guideline 32, 2006) (Table 2). ${ }^{30}$

Neurodegenerative diseases present challenges to feeding and nutrition that are significantly different from those of trauma or stroke, but have not previously been extensively studied despite increasingly widespread recommendations for early recourse to PEG in these conditions. We therefore assessed PEG tube placement and outcome in patients with neurodegenerative disease through a retrospective case note review in a single neuroscience center in the UK. Our aim was to review clinical practice and identify potential areas for improvement. In the light of our results, we highlight a number of points that might improve patient safety when planning 
PEG tube placement in patients with neurodegenerative disease.

\section{MATERIALS AND METHODS}

A retrospective case note review was performed. All consecutive cases referred for PEG tube placement by neurologists between 2009 and 2013 were identified from the database held by the Endoscopy Unit at North Bristol National Health Service (NHS) Trust, a regional neuroscience center in the UK. Those patients in whom the indication for PEG was stroke were excluded. No patients with a diagnosis of dementia were referred.

Medical records were reviewed, and outcomes were measured against a pre-determined set of standards including an assessment of FVC, blood tests (analysis of renal function, glucose, liver function tests, bone profile, albumin, coagulation, and C-reactive protein), formal assessment of swallow, and daily checks of the stoma site post-PEG tube insertion. Length of hospital stay, short-term complications (symptoms or signs within 30 days of PEG), and long-term complications (symptoms or signs more 30 days after PEG tube insertion) were recorded. Major complications were defined as per ESPEN guidelines and included sepsis, perforation, and hemorrhage, ${ }^{3}$ as well as mortality. Delay in discharge was defined as $>3$ days.

Statistics were calculated using GraphPad Prism version 6.0 (GraphPad Software Inc., La Jolla, CA, USA). Values of $p<0.05$ were considered statistically significant as determined by Kruskal-Wallis one-way analysis of variance with Dunn's multiple comparisons test or Fisher exact test.

\section{RESULTS}

\section{Patient characteristics}

Forty-two patients were identified. Two (5\%) were excluded because their case records were unavailable (Table 3). All patients had a diagnosis of motor neuron disease (MND), a parkinsonian syndrome (idiopathic Parkinson's disease [PD] or a Parkinson's plus syndrome $[\mathrm{PD}+])$, or multiple sclerosis (MS). The patients were evenly distributed between each of these three disease groupings. The mean duration of follow up was 1.65 years (median, 1.4; maximum, 5). In keeping with the natural history, patients with MND had a shorter disease course from onset of disease to PEG $(p<0.001)$. Patients with MS were younger at the time of PEG tube insertion $(p<0.0005)$. Nineteen patients (48\%) patients died within the follow-up period. The mean time from PEG tube insertion to death was 1.01 years (median, 0.83 ) with no significant difference between the disease groupings in time to death from PEG. No significant differences were found between the sexes in age at PEG tube insertion, time from disease onset to PEG, or time of PEG to death.

\section{PEG insertion}

Patients fasted prior to PEG insertion which was performed under sedation. Esophagogastroduodenoscopy was performed with aspiration of stomach contents and gastric insufflation. The abdominal wall was transilluminated to identify the site for PEG insertion. Using sterile technique, local anesthesia was applied to the skin and the PEG tube was inserted via the "pull" technique. A single dose of a broad-spectrum antibiotic was administered if the patient was not already receiving antibiotics with appropriate gram-positive cover.

Table 3. Cohort Characteristics

\begin{tabular}{|c|c|c|c|c|c|c|}
\hline Disease & $\begin{array}{c}\text { No. of } \\
\text { patients, } \\
n(\%)\end{array}$ & $\begin{array}{l}\text { Sex, male/ } \\
\text { female }\end{array}$ & $\begin{array}{l}\text { Age at PEG tube } \\
\text { insertion, yr, } \\
\text { mean (median) }\end{array}$ & $\begin{array}{c}\text { Time from disease } \\
\text { onset to PEG tube } \\
\text { insertion, yr, mean } \\
\text { (median) }\end{array}$ & $\begin{array}{l}\text { Duration of } \\
\text { follow-up, yr, } \\
\text { mean } \\
\text { (median) }\end{array}$ & $\begin{array}{l}\text { Time from PEG } \\
\text { tube insertion to } \\
\text { death, yr, mean } \\
\text { (median) }\end{array}$ \\
\hline $\begin{array}{l}\text { Parkinson's disease and } \\
\text { related disorders }\end{array}$ & $13(32)$ & $10 / 3$ & $65(64)$ & $\begin{array}{l}\text { IPD } 16.2(18) \\
\text { MSA } 6.3(6) \\
\text { PSP } 6.5(6.5)\end{array}$ & $2.25(1.5)$ & $1.25(1.2)$ \\
\hline Multiple sclerosis & $13(32)$ & $7 / 6$ & $50(52)^{a)}$ & $\begin{array}{c}\text { RRMS } 13(13) \\
\text { PPMS } 10(10) \\
\text { SPMS } 20.4(17.5)\end{array}$ & $1.68(1.4)$ & $1(0.79)$ \\
\hline Motor neuron disease & $14(34)$ & $4 / 9$ & $68(72)$ & $1.2(1)^{\mathrm{a})}$ & $1.02(1.08)$ & $0.93(0.83)$ \\
\hline Total & $40(100)$ & $21 / 18$ & $61(60)$ & $10.2(8)$ & $1.65(1.4)$ & $1.01(0.83)$ \\
\hline
\end{tabular}

PEG, percutaneous endoscopic gastrostomy; IPD, idiopathic Parkinson's disease; MSA, multiple system atrophy; PSP, progressive supranuclear palsy; RRMS, relapsing remitting multiple sclerosis; PPMS, primary progressive multiple sclerosis; SPMS, secondary progressive multiple sclerosis.

${ }^{\text {a) }}$ Statistically significant results. 


\section{Morbidity and mortality associated with PEG insertion}

Eighty-eight percent of patients experienced a complication secondary to PEG tube at some point. Multiple complications occurred in 12 patients (30\%). Short-term complications (within the first 30 days) were observed in 27 patients (68\%), and longterm complications occurred in 11 patients (28\%). Notably, some patients experienced more than one complication (Table 4). Major short-term complications included five cases of respiratory infections, one case of intra-abdominal sepsis, and two cases of wound infections at the stoma site that required antibiotic therapy. Delayed hospital discharge of greater than 6 weeks occurred in two cases (5\%).

The 30 -day mortality was $3 / 40(8 \%)$ (Table 1$)$, and the cause of death was aspiration pneumonia in all three cases. In one patient (with a parkinsonian condition), death occurred within 16 hours of the procedure. Aspiration was attributed to disease progression in the case of one patient with MND in whom discharge was delayed secondary to social factors. A patient with secondary progressive MS died within 10 days of PEG. Longer term survival was determined by the underlying disease process rather than by the presence or absence of complications secondary to PEG tube insertion; MND was associated with significantly increased risk of death (odds ratio
[OR], 11.08; $p<0.05)$.

Relatively few long-term complications, which are defined by adverse events attributable to PEG tube insertion occurring after the first 30 days, were observed (Table 5). Thirty-five percent of patients had major long-term complications including death, although death was not attributable to PEG in this time period. One MND patient elected not to undergo re-siting of PEG when the original tube was removed due to recurrent site infection.

\section{Compliance with standards}

\section{Measurement of FVC}

Documentary evidence for FVC measurement was available in 57\% of patients with MND. Increased incidence of complications was not observed in patients who did not have monitoring.

\section{Availability of blood test results}

All patients had blood test results available at the time of PEG tube insertion although four patients (10\%) did not have a full set of blood tests. ${ }^{30}$ No difference in complication rate existed between those who had a full set of blood tests and those who did not.

Table 4. Short Term Complications (Onset within 30 Days of Percutaneous Endoscopic Gastrostomy Tube Insertion)

\begin{tabular}{|c|c|c|c|c|}
\hline Complication & $\begin{array}{c}\text { Parkinson's disease and } \\
\text { related disorders }\end{array}$ & Multiple sclerosis & $\begin{array}{l}\text { Motor neuron } \\
\text { disease }\end{array}$ & Total \\
\hline \multicolumn{5}{|l|}{ Major } \\
\hline Infection at stoma site & 0 & 1 & 1 & 2 \\
\hline Aspiration pneumonia & 1 & 3 & 1 & 5 \\
\hline Abdominal sepsis & 0 & 0 & 1 & 1 \\
\hline Raised inflammatory markers & 0 & 1 & 0 & 1 \\
\hline Vomiting & 0 & 0 & 1 & 1 \\
\hline Death & 1 & 1 & 1 & 3 \\
\hline Any short term major complication & 2 & 6 & 5 & 13 \\
\hline \multicolumn{5}{|l|}{ Minor } \\
\hline Dislodgement & 1 & 0 & 0 & 1 \\
\hline Pain at stoma site & 3 & 2 & 4 & 9 \\
\hline Discharge/bleeding & 1 & 2 & 1 & 4 \\
\hline Diarrhoea & 0 & 0 & 2 & 2 \\
\hline Constipation & 0 & 0 & 1 & 1 \\
\hline Any short term minor & 5 & 4 & 8 & 17 \\
\hline Any short term complication & 7 & 10 & 13 & 30 \\
\hline No short term complication & 6 & 6 & 2 & 14 \\
\hline
\end{tabular}

Values are presented as number.

Some patients experienced more than one complication. 
Table 5. Long Term Complications (Onset after 30 Days from Percutaneous Endoscopic Gastrostomy Tube Insertion)

\begin{tabular}{|c|c|c|c|c|}
\hline Complication & $\begin{array}{l}\text { Parkinson's disease and } \\
\text { related disorders }\end{array}$ & Multiple sclerosis & $\begin{array}{c}\text { Motor neuron } \\
\text { disease }\end{array}$ & Total \\
\hline \multicolumn{5}{|l|}{ Major } \\
\hline Aspiration pneumonia & 3 & 3 & 1 & 7 \\
\hline Wound infection at PEG site & 1 & 0 & 1 & 2 \\
\hline Death & 0 & 1 & 6 & 7 \\
\hline Any major complication & 4 & 4 & 8 & 16 \\
\hline \multicolumn{5}{|l|}{ Minor } \\
\hline PEG tube change & $\begin{array}{l}3 \text { (infection at site, routine } \\
\text { re-siting, dislodgement) }\end{array}$ & 1 (dislodgement) & 0 & 4 \\
\hline PEG tube removal & 0 & 0 & 1 (infection at site) & 1 \\
\hline Pain associated with PEG use & 1 & 1 & 0 & 2 \\
\hline Hypergranulation & 1 & 0 & 0 & 1 \\
\hline Any minor complication & 5 & 2 & 1 & 8 \\
\hline Any long term complication & 9 & 6 & 9 & 24 \\
\hline No long term complications & 6 & 8 & 4 & 18 \\
\hline
\end{tabular}

Values are presented as number.

Some patients experienced more than one complication.

PEG, percutaneous endoscopic gastrostomy.

\section{Formal swallow assessment}

All patients had a formal swallow assessment by the Speech and Language Therapy team prior to PEG tube insertion, and a gastrostomy was considered appropriate in all.

\section{Stoma site checks}

Documentary evidence of daily stoma site review during in-patient stay was available in 21/40 (53\%) patients. Of the 19 patients who did not have a recorded daily stoma review, seven patients had major complications, and three patients died. However, a significant relationship was not observed between daily stoma site check and risk of death (OR, $0.13 ; p=0.187)$, major complications (OR, $0.52 ; p=0.348$ ), or minor complications (OR, 1.97; $p=0.4601)$.

\section{Patient age}

Eight patients (four PD patients and four MND patients) in our cohort were aged $>75$ years of age, six of whom had major complications (including one death), and the OR for major complications with age $>75$ years was $10.71(p=0.009)$.

\section{Duration of in-patient stay}

Forty percent of patients (16/40) were discharged within 72 hours of PEG placement. Delays in discharge were observed in all disease groups. For those patients whose hospital stay exceeded 3 days, discharge delays were categorized as "social," "medical," or "mixed." Social causes were responsible for 11/24
(46\%) delays and included delays incurred setting up homecare or training carers/patient for PEG tube use. Lack of dietician availability over the weekend may have contributed to this. Complications contributed to delays in 13/24 (54\%). A trend toward longer in-patient stays was observed among those with MS; four patients (10\%) remained as an in-patient for $>1$ month post-PEG tube insertion, which was pre-dominantly attributable to social factors.

\section{Serum albumin}

Not all patients had formal dietetic review prior to PEG tube insertion although all were observed prior to discharge. Albumin levels were recorded pre- (up to 10 days prior to procedure) and post- (up to 1 year) in 36/40 (90\%) of patients. Twenty percent (9/36) were malnourished at the time of PEG tube placement as defined by serum albumin $\leq 30 \mathrm{~g} / \mathrm{L}$. Of the three patients who died within 30 days of PEG, two (67\%) had low albumin levels (29 and $19 \mathrm{~g} / \mathrm{L}$ ). A strong trend toward increased 30-day mortality was found if pre-procedure serum albumin level was $\leq 30 \mathrm{~g} / \mathrm{L}$ (30-day mortality OR, 7.43; $p=0.148$ ). Statistical significance was not reached probably due to the low numbers of deaths. Serum albumin levels improved post-PEG tube placement in all patients for whom data were available. 


\section{DISCUSSION}

Maintaining adequate nutrition remains an important goal in the optimum management of many illnesses, including neurodegenerative diseases. A number of studies have reviewed morbidity and mortality following PEG tube insertion except those with MND; ${ }^{15}$ the studies which have included patients with neurological disease have tended to include them among a wide range of indications for PEG (Table 1). For those with orofacial tumors, gastrointestinal malignancy, and cerebrovascular disease, a PEG tube is typically inserted to primarily provide temporary nutritional support and may be inserted prophylactically when dysphagia and weight loss are anticipated; circumstances are different to those encountered in the context of neurodegenerative disease when neurological deterioration and indefinite use of PEG tube feeding are expected. Outcomes are not therefore directly comparable between neurodegenerative disease and other disease groupings; morbidity and mortality would be expected to be higher in the context of progressive neurological disease. Although the limitations of our study include its retrospective nature and lack of patient and/or carer reported outcome measures, our study is unique in exploring in detail pre- and post-PEG care in a relatively large, contemporaneous cohort of patients with MS and parkinsonian conditions in a single neuroscience center in the UK.

As expected, the 30 -day mortality rate $(8 \%)$ is high when compared with that in studies on head and neck neoplasia but compares favorably with those with more comparable patient cohorts, including those with a high proportion of patients in whom the indication for PEG tube insertion was dementia, stroke, and MND (Table 1).

Concern regarding the relatively high complication rate of PEG tube placement has previously been raised, and the National Patient Safety Agency (NPSA) published a rapid response report (RRR) in March 2010. ${ }^{31}$ The report included recommendations for good practice, such as regular observation post-PEG tube insertion, daily examination, prompt discharge after the procedure, and inclusion of a "Alert Label" in the patient's case record to raise awareness of the early signs of complications among hospital staff as well as patients, relatives, and carers. ${ }^{31}$ This was introduced after the onset of our study, and it would be of interest to know whether the recommendations led to a reduction in morbidity and mortality associated with PEG tube insertion.

We report a relatively high rate of complications. The high rate is likely to be due to multiple factors including the inherent morbidity and poor conditioning associated with neurodegenerative disease, poor baseline nutritional status, ongoing risk factors for aspiration associated with neurodegenerative disease, and long in-patient stay with consequent increased susceptibility to infection but also the opportunity for improved ascertainment of complications.

Previously reported risk factors for PEG tube insertion include increasing age. ${ }^{16,17}$ This finding was replicated in our study; the OR was $>10$ for the risk of major complications in those aged $>75$ years. This result suggests that particular care should be taken when considering PEG tube feeding in the elderly when the indication is progressive neurological disease.

Earlier involvement of nutritional support teams probably leads to earlier consideration of PEG, averting malnutrition and the associated increased risk of morbidity and mortality. Low serum albumin was reported to be a risk factor for death associated with PEG tube insertion, ${ }^{5,17,18,32}$ and a trend toward this was replicated in our study. The low total number of deaths makes statistical analysis unreliable. Other reported prognostic factors that influence PEG outcome include low serum cholesterol level, low lymphocyte count, hyponatremia, and severe comorbidity such as cardiovascular disease. ${ }^{17,33,34}$ Although one study reported that FVC $<65 \%$ is a predictor of poor outcome in MND patients, ${ }^{14}$ no excess morbidity and mortality were reported in other studies in MND patients whose FVC prior to PEG tube insertion is $<50 \%$ predicted. ${ }^{8,19,20,35}$ One group reported that periprocedural non-invasive ventilation (NIV) may minimize risk of PEG tube placement in subjects with FVC $<50 \%,{ }^{19}$ and the ESPEN guidelines recommended that PEG tube placement be considered prior to the FVC falling below $50 \%$ predicted. ${ }^{3}$ No data are available regarding FVC measurement in patients with other neurological diseases in whom PEG tube insertion is being considered. FVC was not routinely measured in our cohort when the indication for PEG tube placement was a condition other than the MND.

Radiologically inserted gastrostomy (RIG) is an alternative to PEG tube insertion. An advantage of RIG is that the procedure can be undertaken while the patient receives respiratory support with NIV. ${ }^{36,37}$ Allen et al. $^{20}$ reported lower failure rates of RIG tube insertion ( $16 \%$ vs. $2 \%$ ), but failure to site PEG was not a complication observed in our study. More significantly, however, RIG tube placement was less frequently associated with aspiration (11\% vs. $0 \%),{ }^{20}$ although Shaw et al. ${ }^{38}$ reported equivalent post-procedural survival for patients with MND who underwent RIG or PEG tube insertion. Peroral image-guided gastrostomy (PIG) is a hybrid technique that has been utilized with MND patients with the possibility of concomitant use of NIV, with rates of complications comparable to PEG (21\% in PIG and 23\% in PEG), with no reported life-threatening complications and no significant survival differences in this study. ${ }^{39}$ In a recent large 
Table 6. Points for Consideration

Appropriate selection of patient for PEG tube insertion by discussion of neurologist with nutritional team/gastroenterology

Pre-admission work-up to anticipate and avoid potential causes of discharge delays

For patients with MND, FVC should be performed and documented. Consideration of PEG tube insertion should be given particular care if $\mathrm{FVC}$ is $<50 \%$ predicted or there is shortness of breath on minimal exertion.

Consider FVC measurement in all patients with neurological disease in whom PEG tube insertion is being considered.

Results for full blood count, renal function, liver function, bone profile, clotting, C-reactive protein, albumin, and glucose levels should be available prior to PEG tube insertion.

All patients must have nutritional and swallowing assessment prior to PEG tube insertion with ongoing input postprocedure to facilitate home-care training and optimisation of nutrition.

All patients must have valid and written consent.

Post-PEG care should include regular observations, the frequency of which should be tailored to the individual patient.

Daily stoma site review and regular examination of the chest and abdomen should be undertaken and documented post-PEG tube insertion.

Patients and their carers should be informed of the risks of PEG tube insertion, and be warned of 'red flag' symptoms such as external leakage of gastric contents or severe pain postprocedure.

Patients should spend the first 24 hours postprocedure on a specialised ward where staff are familiar with postinsertion procedures and 'red flag' symptoms.

Supported discharge should occur following senior review and within 72 hours of PEG tube insertion. The discharge coordinator should be notified of any potential causes of delay.

Prospective data recording including patient and/or carer reported outcome measures should be undertaken.

Points for particular consideration regarding PEG insertion in patients with neurodegenerative disease (modified by the authors from standards included in guidelines issued by National Institute for Health and Clinical Excellence, European Society of Clinical Nutrition and Metabolism, and National Patient Safety Agency. ${ }^{3,30,31}$

PEG, percutaneous endoscopic gastrostomy; MND, motor neuron disease; FVC, forced vital capacity.

prospective cohort study of amyotrophic lateral sclerosis, comparison of the three methods of gastrostomy insertion (PEG, RIG, and PIG) showed no difference in 30-day mortality, survival times, or periprocedural complications, apart from higher perioperational distress experienced by patients undergoing PEG tube insertion. Mortality in this context was associated with increasing patient age at the onset of the disease and percentage of weight loss from diagnosis to the time point of gastrostomy. ${ }^{15}$

This study provides a snapshot of the safety and utility of PEG in a single neuroscience center in the UK as well as highlights key aspects of care that can be optimized to improve morbidity and mortality, particularly for those patients with neurodegenerative disease. Careful patient selection, optimal timing of PEG tube insertion, and periprocedural care with comprehensive education of patients and carers as well as prompt, well-supported hospital discharge, would be expected to reduce morbidity, mortality, and cost-effectiveness. In light of this, we have outlined points of consideration for clinicians considering PEG tube insertion in patients with degenerative neurological disease (Table 6). Future prospective studies could explore a larger cohort of patients including those who have PEG tube insertion outside a tertiary re- ferral center, incorporate data regarding comorbidities, such as cardiac risk factors ${ }^{17}$ and patient and/or carer reported outcomes, and assess value added by input from a dedicated nutrition team and radiological guidance of gastrostomy tube insertion.

Conflicts of Interest

The authors have no financial conflicts of interest.

\section{Acknowledgments}

We are grateful for the input of the Endoscopy Unit, the Quality Improvement and Clinical Audit Department and consultant neurologists at North Bristol NHS Trust. We would especially like to thank Dr. Andria Merrison, Helen Madden, and Pina Watkins. P.S. and C.M.R. receive support from the Burden Neurological Institute.

\section{REFERENCES}

1. Ponsky JL, Gauderer MW. Percutaneous endoscopic gastrostomy: indications, limitations, techniques, and results. World J Surg 1989;13:165170 .

2. Löser C, Wolters S, Fölsch UR. Enteral long-term nutrition via percutaneous endoscopic gastrostomy (PEG) in 210 patients: a four-year prospective study. Dig Dis Sci 1998;43:2549-2557.

3. Löser C, Aschl G, Hébuterne X, et al. ESPEN guidelines on artificial enteral nutrition: percutaneous endoscopic gastrostomy (PEG). Clin Nutr 
2005;24:848-861

4. Mazzini L, Corrà T, Zaccala M, Mora G, Del Piano M, Galante M. Percutaneous endoscopic gastrostomy and enteral nutrition in amyotrophic lateral sclerosis. J Neurol 1995;242:695-698.

5. Hull MA, Rawlings J, Murray FE, et al. Audit of outcome of long-term enteral nutrition by percutaneous endoscopic gastrostomy. Lancet 1993; 341:869-872.

6. Löser C. Clinical aspects of long-term enteral nutrition via percutaneous endoscopic gastrostomy (PEG). J Nutr Health Aging 2000;4:47-50.

7. Britton JE, Lipscomb G, Mohr PD, Rees WD, Young AC. The use of percutaneous endoscopic gastrostomy (PEG) feeding tubes in patients with neurological disease. J Neurol 1997;244:431-434.

8. Spataro R, Ficano L, Piccoli F, La Bella V. Percutaneous endoscopic gastrostomy in amyotrophic lateral sclerosis: effect on survival. J Neurol Sci 2011;304:44-48.

9. Luman W, Kwek KR, Loi KL, Chiam MA, Cheung WK, Ng HS. Percutaneous endoscopic gastrostomy: indications and outcome of our experience at the Singapore General Hospital. Singapore Med J 2001;42:460465.

10. James A, Kapur K, Hawthorne AB. Long-term outcome of percutaneous endoscopic gastrostomy feeding in patients with dysphagic stroke. Age Ageing 1998;27:671-676.

11. Burney RE, Bryner BS. Safety and long-term outcomes of percutaneous endoscopic gastrostomy in patients with head and neck cancer. Surg Endosc 2015;29:3685-3689.

12. Khokhar N, Gill ML. Percutaneous endoscopic gastrostomy: nine years experience in a tertiary care centre in Pakistan. J Pak Med Assoc 2005; 55:108-110.

13. Sanders DS, Carter MJ, D'Silva J, James G, Bolton RP, Bardhan KD. Survival analysis in percutaneous endoscopic gastrostomy feeding: a worse outcome in patients with dementia. Am J Gastroenterol 2000;95:14721475.

14. Chiò A, Finocchiaro E, Meineri P, Bottacchi E, Schiffer D. Safety and factors related to survival after percutaneous endoscopic gastrostomy in ALS. ALS Percutaneous Endoscopic Gastrostomy Study Group. Neurology 1999;53:1123-1125.

15. ProGas Study Group. Gastrostomy in patients with amyotrophic lateral sclerosis (ProGas): a prospective cohort study. Lancet Neurol 2015;14:702709.

16. Arora G, Rockey D, Gupta S. High In-hospital mortality after percutaneous endoscopic gastrostomy: results of a nationwide population-based study. Clin Gastroenterol Hepatol 2013;11:1437-1444.e3.

17. Janes SE, Price CS, Khan S. Percutaneous endoscopic gastrostomy: 30day mortality trends and risk factors. J Postgrad Med 2005;51:23-28.

18. Tominaga N, Shimoda R, Iwakiri R, et al. Low serum albumin level is risk factor for patients with percutaneous endoscopic gastrostomy. Intern Med 2010;49:2283-2288.

19. Czell D, Bauer M, Binek J, Schoch OD, Weber M. Outcomes of percutaneous endoscopic gastrostomy tube insertion in respiratory impaired amyotrophic lateral sclerosis patients under noninvasive ventilation. Respir Care 2013;58:838-844.

20. Allen JA, Chen R, Ajroud-Driss S, et al. Gastrostomy tube placement by endoscopy versus radiologic methods in patients with ALS: a retrospective study of complications and outcome. Amyotroph Lateral Scler Frontotemporal Degener 2013;14:308-314.

21. Rabeneck L, Wray NP, Petersen NJ. Long-term outcomes of patients receiving percutaneous endoscopic gastrostomy tubes. J Gen Intern Med 1996;11:287-293.

22. Leeds JS, McAlindon ME, Grant J, Robson HE, Lee FK, Sanders DS. Survival analysis after gastrostomy: a single-centre, observational study comparing radiological and endoscopic insertion. Eur J Gastroenterol Hepatol 2010;22:591-596.
23. Nicholson FB, Korman MG, Richardson MA. Percutaneous endoscopic gastrostomy: a review of indications, complications and outcome. J Gastroenterol Hepatol 2000;15:21-25.

24. Zalar AE, Guédon C, Piskorz EL, Sánchez Basso A, Ducrotté P. Percutaneous endoscopic gastrostomy in patients with neurological diseases. Results of a prospective multicenter and international study. Acta Gastroenterol Latinoam 2004;34:127-132.

25. Shimizu T, Hanaoka T, Hayashi H, Inoue H, Imamura K, Oyanagi K. Percutaneous endoscopic gastrostomy in patients with intractable neurological diseases--retrospective study of the indication, complication and prognosis. Rinsho Shinkeigaku 2007;47:565-570.

26. Rio A, Ellis C, Shaw C, et al. Nutritional factors associated with survival following enteral tube feeding in patients with motor neurone disease. J Hum Nutr Diet 2010;23:408-415.

27. Forbes RB, Colville S, Swingler RJ; Scottish Motor Neurone Disease Research Group. Frequency, timing and outcome of gastrostomy tubes for amyotrophic lateral sclerosis/motor neurone disease: a record linkage study from the Scottish Motor Neurone Disease Register. J Neurol 2004;251:813-817.

28. Russ KB, Phillips MC, Wilcox CM, Peter S. Percutaneous endoscopic gastrostomy in amyotrophic lateral sclerosis. Am J Med Sci 2015;350:9597.

29. Cullinane M, Gray AJ, Hargraves CM, et al. The 2004 Report of the National Confidential Enquiry into Patient Outcome and Death. London: NCEPOD; 2004.

30. National Collaborating Centre for Acute Care (Great Britain); National Institute for Health and Clinical Excellence (Great Britain). Nutrition Support in Adults: Oral Nutrition Support, Enteral Tube Feeding and Parenteral Nutrition. London: National Institute for Health and Clinical Excellence; 2006.

31. NHS National Patient Safety Agency. Rapid response report NPSA/2010/ RRR010: early detection of complications after gastrostomy [Internet]. Redditch: NHS; c2010 [cited 2016 Sep 19]. Available from: http://www. nrls.npsa.nhs.uk/EasySiteWeb/getresource.axd?AssetID=73759\&servicetype $=$ Attachment\&type $=$ full.

32. Lucendo AJ, Friginal-Ruiz AB. Percutaneous endoscopic gastrostomy: an update on its indications, management, complications, and care. Rev Esp Enferm Dig 2014;106:529-539.

33. Poulsen M, Trezza M, Atimash GH, et al. Risk factors for morbidity and mortality following gastroenterostomy. J Gastrointest Surg 2009;13:12381244.

34. Onishi J, Kuzuya M, Sakaguchi H. Survival rate after percutaneous endoscopic gastrostomy in a long-term care hospital. Clin Nutr 2004;23:12481249.

35. Sarfaty M, Nefussy B, Gross D, Shapira Y, Vaisman N, Drory VE. Outcome of percutaneous endoscopic gastrostomy insertion in patients with amyotrophic lateral sclerosis in relation to respiratory dysfunction. Amyotroph Lateral Scler Frontotemporal Degener 2013;14:528-532.

36. Thornton FJ, Fotheringham T, Alexander M, Hardiman O, McGrath FP, Lee MJ. Amyotrophic lateral sclerosis: enteral nutrition provision: endoscopic or radiologic gastrostomy? Radiology 2002;224:713-717.

37. Chiò A, Galletti R, Finocchiaro C, et al. Percutaneous radiological gastrostomy: a safe and effective method of nutritional tube placement in advanced ALS. J Neurol Neurosurg Psychiatry 2004;75:645-647.

38. Shaw AS, Ampong MA, Rio A, et al. Survival of patients with ALS following institution of enteral feeding is related to pre-procedure oximetry: a retrospective review of 98 patients in a single centre. Amyotroph Lateral Scler 2006;7:16-21.

39. Chavada G, El-Nayal A, Lee F, et al. Evaluation of two different methods for per-oral gastrostomy tube placement in patients with motor neuron disease (MND): PIG versus PEG procedures. Amyotroph Lateral Scler 2010;11:531-536. 